\title{
Prostate cancer patients' experience and preferences for acquiring information early in their care
}

Deb Feldman-Stewart, $\mathrm{PhD}^{1}$; Christine Tong, $\mathrm{MA}^{1}$; Michael Brundage, MD, $\mathrm{MSc}^{1}$; Jackie Bender, $\mathrm{PhD}^{2}$; John Robinson, $\mathrm{PhD}^{3}$

${ }^{1}$ Queen's University, Kingston, ON; ${ }^{2}$ University Health Network, Toronto, ON; ${ }^{3}$ Tom Baker Cancer Centre, Calgary, AB; Canada

Acknowledgements: The authors would like to thank Robert C. Hornik and Rebekah H. Nagler for their immediate willingness to share their survey and details of their methods. They would also like to thank the Cancer Registries of British Columbia, Alberta, Saskatchewan, and Ontario for their assistance in this study.

Funding: This work was awarded by Prostate Cancer Canada and is proudly funded by Movember.

Cite as: Can Urol Assoc J 2018 Feb. 6; Epub ahead of print. http://dx.doi.org/10.5489/cuaj.4754

Published online February 6, 2018

$* * *$

Abstract

Introduction: Prostate cancer patients' information needs are well-described, but little is known about their preferred sources and media for obtaining information. We sought to determine prostate cancer patients' experiences and preferences for acquiring information after diagnosis, a time of high information need.

Method: Population surveys were conducted in four Canadian provinces in 2014-15. Each provincial cancer registry surveyed a random sample of prostate cancer patients diagnosed in late 2012.

Results: A total of 1366 patients responded across provinces. Respondents most frequently tried to obtain information from their urologist; $86 \%$ found that easy and $9 \%$ found it difficult. Seventy-nine percent of respondents who saw only a urologist felt well-informed compared to $86 \%$ of those who saw both a urologist and a radiation oncologist. $85 \%$ of respondents wanted printed information; 68\% wanted it electronically. Respondents' most frequent barriers to obtaining information from physicians were: not actually having enough time (31\%), worrying about having enough time (23\%), and worrying about asking too many questions (18\%). Their most frequent barriers related to internet/printed information, respectively, were uncertainty about quality (63\%/49\%) and unclear if personally applicable (56\%/49\%). Recommended facilitators were having a navigator (85\%), providing printed information (85\%), and someone to answer questions: in person (90\%), by phone (66\%), or via email (58\%). 
Conclusions: Prostate cancer patients want urologists to provide them with information and are more likely to report being informed if they see both a urologist and a radiation oncologist. Optimal information provision requires that it be provided both on the internet and in print.

\section{Introduction}

Most men want information about their disease and treatment options following a prostate cancer diagnosis. Previous research shows that for groups of prostate cancer patients, information needs are remarkably similar across time ${ }^{1}$ and across different developed countries. ${ }^{2}$ Across individuals, however, information needs vary substantially, as do the reasons for wanting information (e.g., better understanding, making treatment decisions, etc). ${ }^{3}$

Recent research suggests that providing adequate support to prostate cancer patients at diagnosis often remains a challenge. ${ }^{4}$ Identifying whom patients prefer to go to for information, when they want it, and in what medium they prefer to receive it, could inform the design of support strategies. One population study of prostate cancer patients found that $83 \%$ sought information from their treating doctors, $40 \%$ consulted paper sources (books and pamphlets) and

only $12 \%$ used the internet ${ }^{5}$ but those data were collected over a decade ago. On-line information provision is seen as being easier to update and disseminate, but these benefits may not be realizable with this demographic group. For example, 2012 data revealed that only $47.5 \%$ of Canadians $>65$ years old used the internet at all. ${ }^{6}$

The objectives addressed in this report were to determine the experience and preferences of prostate cancer patients around sources of information in the diagnosis-to-decision time interval, along with barriers and facilitators of their preferred access.

\section{Methods}

Population surveys of prostate cancer patients were conducted in four provinces, British Columbia (BC), Alberta (AB), Saskatchewan (SK) and Ontario (ON), in 2014-15 using their respective provincial cancer registries. We sought to obtain responses from $10 \%$ of provincial patients. The expected response rate was $30 \%$, thus, each registry invited a random selection of $55-60 \%$ of men diagnosed with prostate cancer in the last half of 2012 in their registry to participate in the study.

Three registries (BC, AB, SK) used an opt-out recruiting strategy, providing a cover letter introducing the study with the survey, making clear that completing it was optional. The fourth registry $(\mathrm{ON})$ used an opt-in strategy, providing a letter introducing the study and required the recipient to phone the registry to volunteer for the study, in order for the survey to be sent. Survey packages in all provinces included an addressed, stamped envelope for returning the completed survey. After four weeks, a second survey package was sent to non-respondents. 
The survey focussed on several themes. These include information and decision making just after diagnosis, current needs (approximately two years after diagnosis), internet use, and background information. This report is focussed on information just after diagnosis. Each of the 10 relevant survey questions (labelled "Q"+number) and its response options, as presented in the survey, are shown in Table 1.

\section{Results}

Response rates for the opt-out provinces were $46 \%-55 \%$, and for the opt-in province was $13 \%$ (total $\mathrm{N}=1366$ ). Table 2 shows respondents' demographic and health characteristics. As the table shows, most characteristics were similar across provinces. ON had a higher percentage of respondents with university education and SK had a lower percentage who lived in urban/suburban settings.

The distribution of responses for each information-related question is shown in Table 1 except Q2 and Q4 which are presented in Figure 1 for the person-related sources, and Table 3 for the media.

As can be seen in Table $1 \mathrm{Q} 1,80 \%$ of respondents searched for information, either alone or with others, and only $1 \%$ did not want any information about prostate cancer and its treatments.

\section{Sources of information}

Figure 1 shows eleven potential person-related sources of information for use just after diagnosis. For each source, the left-hand axis shows the percentage of respondents that used that source, divided into the percentages that found it easy, that found it difficult, and that did not try to use it. The right-hand axis shows, for each source, the percentage of respondents who would have liked to use it, if it was easy to do so. As the figure shows, the urologist was the most frequently used source, with $86 \%$ finding doing so was easy or very easy. Importantly, if it were easy to do so, $96 \%$ of respondents would have wanted to obtain information from their urologist. The most frequent barriers to patients requesting information from their doctors (Table 1 Q5) were: 31\% did not actually have enough time with their doctor, 23\% worried about not having enough time, and $18 \%$ worried about asking too many questions.

Sources not dependent on specific people (the internet and on paper) are shown in Table 3. As the table shows (Q2), internet sources were used less frequently (65\%) than print sources (81\%). Importantly, if it were easy to do so, $68 \%$ would have liked internet information while $85 \%$ would have liked to have printed information (Q4). In fact, $63 \%$ of respondents would have liked both internet and printed information.

Barriers to obtaining information from the internet and from print were similar (Table 1 Q6 and Q7). The most frequent barriers were: not knowing how to judge the quality of the information (internet 63\%, print 49\%) and not knowing if the information applied to them personally (internet 56\%, print 49\%). 
The most frequently recommended facilitators to overcome barriers (Table 1 Q8) were having a navigator (85\%), printed information (85\%), and someone to answer questions: in person (90\%), by phone (66\%) or email (58\%).

Feeling informed

Eighty percent of respondents felt well informed about prostate cancer and its potential treatments (Table 1 Q3); 19\% felt only somewhat/poorly informed. Less than $1 \%$ of respondents did not want to be informed.

Interestingly, $79 \%$ of those who saw only a urologist felt well informed compared to $86 \%$ of those who saw both a urologist and a radiation oncologist ( $p<.05$ ), while $21 \%$ of those who saw only a urologist compared to $14 \%$ of those who saw both specialists felt only somewhat or poorly informed $(p<.05), \chi^{2}=7.75, p=.02$.

In contrast, the same percentages of patients who saw a urologist and a medical oncologist as who saw only a urologist felt well informed (79\%) and the same percentages felt poorly informed $(21 \%), \chi^{2}=0.08, p=.96$.

\section{Information received}

Table 4 shows, for each treatment, the number of respondents who received information about it (Q9) and the number of respondents who actually received that treatment (Q10). As can be seen, $40 \%$ of respondents had surgery while $75 \%$ received information about it, and 31\% had external beam radiation treatment (EBRT) while $65 \%$ received information about it. In fact, only $2 \%$ of those who had surgery and $5 \%$ of those who had EBRT, reported not receiving information about the treatment they received.

The other treatments were received by one-quarter of respondents or less (Table 3), and higher percentages of those groups reported not receiving information about their treatment: $10 \%$ on ADT, $13 \%$ on Active Surveillance, $13 \%$ on Watchful Waiting, and $19 \%$ on chemotherapy. Interestingly, while $98 \%$ of those who underwent surgery reported receiving information about surgery, only $64 \%$ of them reported receiving information about EBRT, typically an option for those eligible for surgery.

\section{Provincial comparisons}

Table 5 shows the response distributions of the four provinces to the most frequently chosen sources, barriers and facilitators. It includes the top four person-specific sources: urologists, general practitioners, other cancer patients, and radiation oncologists. As can be seen, the response distributions for each of the sources are very similar across the provinces, both ease of obtaining the information and preference to use that source if it were easy to do so.

Table 5 also includes results for the top barriers to obtaining information from each of three types of sources: person-specific sources, the internet, and non-internet public sources such as books and pamphlets. Again, all of the response distributions are very similar across the provinces. In addition, the table shows that the top 2 barriers to obtaining information from the 
internet were the same as the top 2 barriers to obtaining printed information: (1) concern about judging the quality of the information (a problem with the internet for $63 \%$ of respondents overall, and with printed information for $49 \%$ of respondents overall), and (2) whether the information applied to them (a problem with the internet for $56 \%$ of respondents overall, and with printed information for $49 \%$ of respondents overall) .

Table 5 also shows results for the top 2 facilitators. Again, the percentage that reported each of the facilitators to be helpful was similar across provinces.

Finally, Table 5 shows results for the two indicators of the patients' experience with information. The first is the percentage of respondents in each province who felt well informed and, as can be seen, these percentages also are very similar across the four provinces. The second is the percentage of patients who underwent only surgery and reported receiving information about EBRT, and that too did not differ substantially across provinces.

\section{Discussion}

Our results show that the most frequently preferred information source, urologists, was valued by essentially all of our respondents, consistent with the pivotal role of urologists in informing prostate-cancer patients, disclosing the diagnosis and stage, and initially presenting treatment options. However, anticipating and receiving biopsy results typically creates high anxiety in these patients, which in turn affects their ability to process information ${ }^{7}$ at the time that the urologist may be trying to provide it. Thus, not only is the pivotal role of urologists in informing patients clear but so are the challenges faced by urologists.

Our data were collected in the context of different provincial healthcare systems. Further, because Ontario's provincial registry demanded a recruiting strategy that was more onerous for patients, its response rate was very low compared to the other provinces. Despite the differences in healthcare systems and recruiting strategies, response distributions across the provinces were remarkably consistent. The similarity suggests that the data are valid, meaning that the Ontario data are also likely to be a reasonable representation of the province's prostate cancer patients' responses.

Essentially all respondents treated with surgery received information about surgery and four-fifths of them reported feeling well informed about their options, an indication of the success of many encounters in meeting patients' needs. The remaining one-fifth felt poorly informed but our data do not clarify why.

Our data do indicate that a larger percentage of patients who saw both a radiation oncologist and a urologist felt well informed compared to the percentages of those who saw only a urologist (and a lower percentage felt poorly informed). We note that the RAND Corporation proposed a quality indicator of good process that the diagnosing urologist has “... offered [the patient] the opportunity to consult with .... a radiation oncologist or medical oncologist (if provider is urologist)". ${ }^{8}$ Our data do not address compliance with this indiciator directly but the rationale for the directive is increased information provided to patients about EBRT. The fact, therefore, that 
only two-thirds of our respondents who were treated with only surgery reported receiving information about EBRT is a bit concerning---a rate that appears similar across the provinces. Together, these findings suggest the need for and demonstrate the benefits of multidisciplinary management of these patients to improve the likelihood that they feel as informed as possible across all four provinces.

The top barriers to obtaining information from doctors relate to time, either limited actual time or worry about using it. The top facilitators, having someone to answer questions and being provided with printed information, would address those concerns. Furthermore, if the printed information and /or the person answering the patient's questions happen within the context of that patient's care, the patient can be assured about the quality of the information and that it is pertinent to him, two of the most frequent barriers they encountered when trying to obtain additional information.

The need for frequent updating of the information on prostate cancer and its treatments, and the need for flexible access make it appealing to offer information electronically. However, one-third our respondents made clear that they do not want information from the internet, and $63 \%$ would like to receive information in both media. The large overlap in preferred medium suggests that the two media serve different purposes and producing the information in both media is a strategy that would facilitate reaching the greatest number of patients, and help them address their individual purposes for the information.

Taken together, our results suggest several ways to potentially improve provision of patient information in the diagnosis-to-treatment decision interval of prostate cancer care. Urologists are clearly a very valued source. However, our results also suggest that their information provision has room to improve. Use of multidisciplinary clinics and directing patients to additional information may be helpful, particularly if recommended by urologists or other healthcare providers, a strategy that addresses patients' concerns about the quality of the information, and whether the information is relevant to their particular situation. Further, making it available both on the internet and on paper would help patients to address their various individual purposes for the information. While these strategies are already used individually in some locations, our data supports using them together as part standard practice. 


\section{References}

1. Feldman-Stewart D, Brennenstuhl S, Brundage MD, Siemens DR. Overall information needs of early-stage prostate cancer patients over a decade: highly variable and remarkably stable. Supportive Care in Cancer 2009;17(4):429-435.

2. Feldman-Stewart D, Capirci C, Brennenstuhl S et al. Information needs of early-stage prostate cancer patients: A comparison of nine countries. Radiotherapy and Oncology 2010;94:328-333.

3. Feldman-Stewart D, Brundage MD, Hayter $\mathrm{C}$ et al. What questions do patients with curable prostate cancer want answered? Medical Decision Making 2000;20(1):7-19.

4. Lehto US, Helander S, Taari K, Aromaa A. Patient experiences at diagnosis and psychological well-being in prostate cancer: A Finnish national survey. European Journal of Oncology Nursing 2015;19:220-229.

5. Nagler RH, Gray SW, Romantan A et al. Differences in information seeking among breast, prostate, and colorectal cancer patients: Results from a population-based study. Patient Education and Counseling 2010;81S:S54-S62.

6. Statistics Canada. Canadian Internet use survey, Internet use, by location of use, household income and age group for Canada and regions, Table 358-0154, CANSIM (database). 2012. http://www5.statcan.gc.ca/cansim/a26?lang=eng\&id=3580154, Statistics Canada. 920-2016.

7. Dillard AJ, Scherer LD, Ubel PA, Alexander S, Fagerlin A. Anxiety symptoms prior to a prostate cancer diagnosis: Associations with knowledge and openness to treatment. British Journal of Health Psychology 2017;22:151-168.

8. Litwin MS, Steinberg M, Malin J et al. Prostate cancer patient outcomes and choice of providers: Development of an infrastructure for quality assessment. Rand Report, Prepared for the Bing Fund 2000;1-248. 
Figures and Tables

Fig. 1. Respondents' experiences and desires to use various person-specific sources of information.

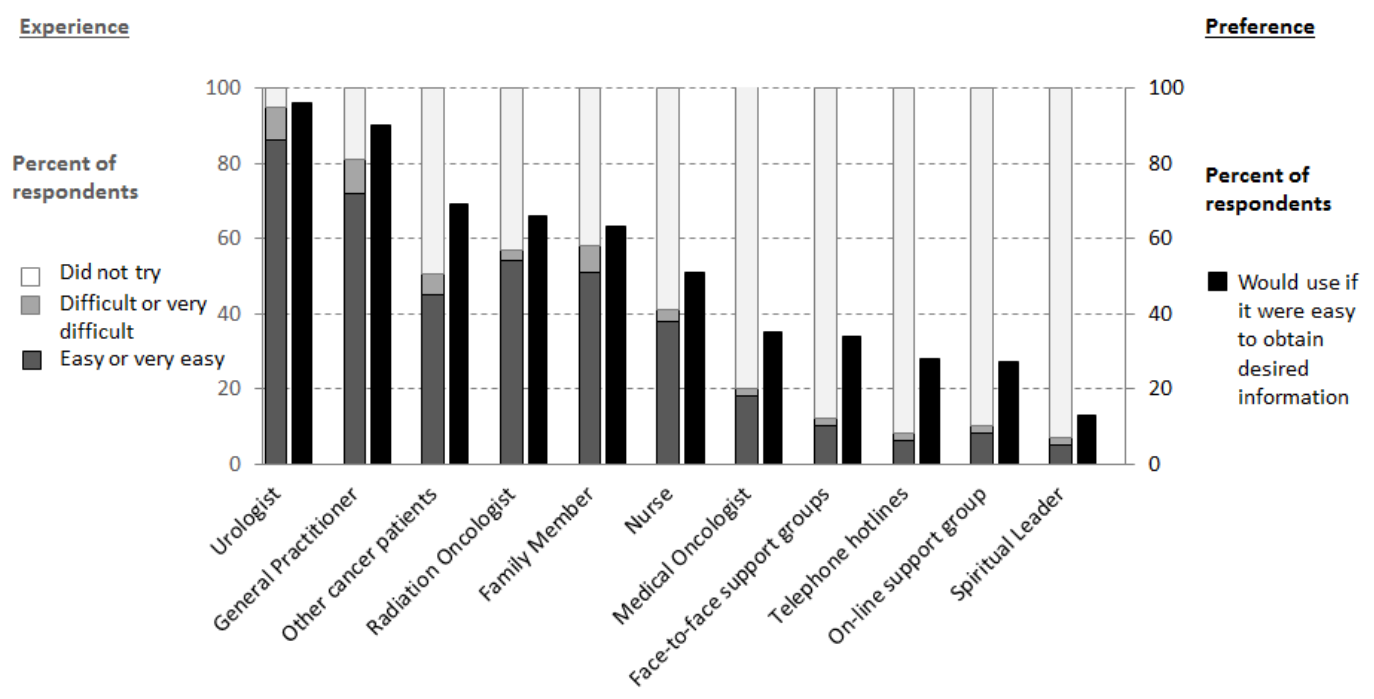

Information Source 
Table 1. Information-related questions (Q1-Q8), their response options, and distributions of responses

Q1. Who looked for information about prostate cancer and its treatments for you? ${ }^{1}$

\begin{tabular}{|c|c|c|c|c|}
\hline & $\begin{array}{c}\text { "Someone else did most } \\
\text { or all looking for } \\
\text { information" }\end{array}$ & $\begin{array}{c}\text { "I did some looking for } \\
\text { information myself and } \\
\text { someone else did some of it } \\
\text { for me" }\end{array}$ & $\begin{array}{c}\text { "I did most or all of } \\
\text { the looking for } \\
\text { information myself” }\end{array}$ & $\begin{array}{c}\text { "I did not want any } \\
\text { information about } \\
\text { prostate cancer and its } \\
\text { treatments" }\end{array}$ \\
\hline $256(20 \%)$ & $484(37 \%)$ & $533(41 \%)$ & $18(1 \%)$ \\
\hline
\end{tabular}

Q2. How easy or difficult was it for you (or other people helping you) to get information from each of the following sources below? ${ }^{2}$ (Results shown in Fig. 1 and Table 4)

Q3. How well-informed did you feel about prostate cancer and its treatments? ${ }^{1}$

\begin{tabular}{|c|c|c|c|}
\hline & "I felt very well-informed" \\
or "I felt well-informed" & $\begin{array}{c}\text { "I felt only somewhat informed" or } \\
\text { "I felt poorly informed" }\end{array}$ & $\begin{array}{c}\text { "I did not want to be informed } \\
\text { about prostate cancer and its } \\
\text { treatments" }\end{array}$ \\
\hline $1069(80 \%)$ & $257(19 \%)$ & $4(0 \%)$ \\
\hline
\end{tabular}

Q4. If you had easy access to each of the following sources, how much would you have wanted to get information about prostate cancer and/or treatments from each source? ${ }^{2}$ (Results shown in Fig. 1 and Table 4)

Q5. Overall, how much of a problem was each of the following factors when you tried to get the information that you wanted from your doctor or nurse? ${ }^{2}$

\begin{tabular}{|c|c|c|c|}
\hline Factor & $\begin{array}{c}\text { "No } \\
\text { problem" }\end{array}$ & $\begin{array}{l}\text { "Somewhat of a } \\
\text { problem" } \\
\text { or "Big Problem" }\end{array}$ & $\begin{array}{l}\text { "Not } \\
\text { sure" }\end{array}$ \\
\hline $\begin{array}{l}\begin{array}{l}\text { Being worried about taking up a lot of my doctor's } \\
\text { time }\end{array} \\
\end{array}$ & $941(74 \%)$ & $293(23 \%)$ & $43(3 \%)$ \\
\hline Being worried about taking up a lot of my nurse's time & $697(62 \%)$ & $116(10 \%)$ & $313(28 \%)$ \\
\hline Not actually having enough time with my doctor & $791(64 \%)$ & $371(31 \%)$ & $53(4 \%)$ \\
\hline Not actually having enough time with my nurse & $628(58 \%)$ & $129(12 \%)$ & $333(31 \%)$ \\
\hline $\begin{array}{l}\text { Being worried about upsetting my doctor with too } \\
\text { many questions }\end{array}$ & $943(78 \%)$ & $219(18 \%)$ & $53(4 \%)$ \\
\hline Language barrier & $126(88 \%)$ & $13(5 \%)$ & $84(3 \%)$ \\
\hline My doctor or nurse was hard to understand & $1024(87 \%)$ & $78(7 \%)$ & $71(6 \%)$ \\
\hline Other: Please specify & & & \\
\hline \multicolumn{4}{|c|}{$\begin{array}{l}\text { Q6. Overall, how much of a problem was each of the following factors when you tried to get the } \\
\text { information that you wanted from the internet? }\end{array}$} \\
\hline Factor & $\begin{array}{c}\text { "No } \\
\text { problem" }\end{array}$ & $\begin{array}{l}\text { "Somewhat of a } \\
\text { problem" or "Big } \\
\text { Problem" }\end{array}$ & $\begin{array}{l}\text { "Not } \\
\text { sure" }\end{array}$ \\
\hline $\begin{array}{l}\text { Having no access to computer or mobile device (e.g. } \\
\text { iPad) }\end{array}$ & $939(88 \%)$ & $86(8 \%)$ & $46(4 \%)$ \\
\hline Not having high-speed internet connection & $911(87 \%)$ & $93(9 \%)$ & $43(4 \%)$ \\
\hline Not know how or where to search & $701(67 \%)$ & $296(28 \%)$ & $48(5 \% 0$ \\
\hline
\end{tabular}




\begin{tabular}{|c|c|c|c|}
\hline $\begin{array}{l}\text { Not being comfortable using a computer or mobile } \\
\text { device (e.g., tablet, iPad) }\end{array}$ & $841(80 \%)$ & 177 (17\%) & $37(4 \%)$ \\
\hline Being worried about costs & $913(88 \%)$ & $82(8 \%)$ & $39(4 \%)$ \\
\hline $\begin{array}{l}\text { Not knowing how to judge the quality of the } \\
\text { information or what I could trust }\end{array}$ & $340(32 \%)$ & $655(63 \%)$ & $53(5 \%)$ \\
\hline $\begin{array}{l}\text { Not knowing what information applied to my } \\
\text { situation }\end{array}$ & $422(40 \%)$ & $585(56 \%)$ & $47(4 \%)$ \\
\hline Not having time to search & $842(82 \%)$ & $149(14 \%)$ & $40(4 \%)$ \\
\hline Difficulty reading, viewing, or printing information & $871(84 \%)$ & $131(1$ & $29(3 \%)$ \\
\hline Difficulty finding information that I ce & $699(67 \%)$ & & $4 \%)$ \\
\hline $\begin{array}{l}\text { Other: Pease } \\
\text { specify }\end{array}$ & & & \\
\hline Did not try to get information from the interne & $\square$ & & \\
\hline \multicolumn{4}{|c|}{$\begin{array}{l}\text { Q7. Overall, how much of a problem was each of the following factors when you tried to get the } \\
\text { information from public sources other than the internet, such as books, pamphlets, information } \\
\text { sessions etc? }^{2}\end{array}$} \\
\hline Factor & $\begin{array}{l}\text { "No } \\
\text { problem" }\end{array}$ & $\begin{array}{l}\text { "Somewhat of a } \\
\text { problem" or "Big } \\
\text { problem" }\end{array}$ & $\begin{array}{l}\text { "Not } \\
\text { sure" }\end{array}$ \\
\hline rried about costs & $970(85 \%)$ & $119(10 \%)$ & \\
\hline $\begin{array}{l}\text { Not knowing how to judge the quality of the } \\
\text { information or what I could trust }\end{array}$ & $512(46 \%)$ & $543(49 \%)$ & $62(6 \%)$ \\
\hline Not knowing what information applied to me & $514(46 \%)$ & $552(49 \%)$ & $54(5 \%)$ \\
\hline Not knowing how or where to search & 597 (54\%) & $448(41 \%)$ & $56(5 \%)$ \\
\hline Not he & $864(79 \%)$ & $182(17 \%)$ & $41(4 \%)$ \\
\hline $\begin{array}{l}\text { Having difficulty finding information I could } \\
\text { understand }\end{array}$ & $708(65 \%)$ & $338(31 \%)$ & $45(4 \%)$ \\
\hline Other: Please specify & & & \\
\hline Did not try to get information from the internet & $\square$ & & \\
\hline \multicolumn{4}{|c|}{ Q8. How much would each of these have helped you get the information that you wanted? ${ }^{2}$} \\
\hline Factor & $\begin{array}{l}\text { "Not } \\
\text { helpful" }\end{array}$ & $\begin{array}{l}\text { "Somewhat helpful } \\
\text { "or "Very helpful" }\end{array}$ & "Not sure" \\
\hline Having someone & $110(10 \%)$ & $977(85 \%)$ & \%) \\
\hline Having someone $t$ & $66(6 \%)$ & $1061(90 \%)$ & $4 \%)$ \\
\hline $\begin{array}{l}\text { Being able to get my questions answered over the } \\
\text { phone }\end{array}$ & \%) & 736 & $193(17 \%)$ \\
\hline Being able to get my questions answer through email & $236(22 \%)$ & $618(58 \%)$ & $214(20 \%)$ \\
\hline Having printed information & $89(8 \%)$ & $962(85 \%)$ & $75(7 \%)$ \\
\hline \multicolumn{4}{|l|}{ Other: Please specify } \\
\hline Did not try to get information fro & & & \\
\hline
\end{tabular}

${ }^{1}$ The question was followed with the instruction: Pease check BEST response; ${ }^{2}$ The questions was followed with the instruction: Please check BEST response for EACH ROW. 


\begin{tabular}{|c|c|c|c|c|c|}
\hline $\begin{array}{l}\text { Demographic characteristics } \\
\text { (options) }\end{array}$ & Overall & BC & $\mathbf{A B}$ & SK & $\mathbf{O N}$ \\
\hline Age & Mean: 69 years & $71 \mathrm{yr}$ & $68 \mathrm{yr}$ & $69 \mathrm{yr}$ & $70 \mathrm{yr}$ \\
\hline $\begin{array}{l}\text { Partnership status (with } \\
\text { partner, without partner) }\end{array}$ & Mode: $86 \%$ with partner & $85 \%$ & $85 \%$ & $90 \%$ & $88 \%$ \\
\hline $\begin{array}{l}\text { Sexual orientation (gay, } \\
\text { heterosexual, bisexual) }\end{array}$ & Mode: 98\% heterosexual & $97 \%$ & $98 \%$ & $99 \%$ & $98 \%$ \\
\hline $\begin{array}{l}\text { Education (primary, } \\
\text { secondary, college/diploma, } \\
\text { university) }\end{array}$ & $\begin{array}{l}\text { Modes: 33\% college/diploma; } \\
\text { 33\% university }\end{array}$ & $\begin{array}{l}31 \% \\
30 \%\end{array}$ & $\begin{array}{l}38 \% \\
27 \%\end{array}$ & $\begin{array}{l}31 \% \\
31 \%\end{array}$ & $\begin{array}{l}34 \% \\
42 \%\end{array}$ \\
\hline $\begin{array}{l}\text { Residence (urban/suburban, } \\
\text { town/rural) }\end{array}$ & Mode: 63\% urban/suburb; & $67 \%$ & $69 \%$ & $48 \%$ & $61 \%$ \\
\hline $\begin{array}{l}\text { Annual Income }(\leq \$ 20 \mathrm{~K},>\$ 20 \\
-\leq \$ 40 \mathrm{~K},>\$ 40 \mathrm{~K}-\leq \$ 80 \mathrm{~K}, \\
>\$ 80 \mathrm{~K})\end{array}$ & Mode: $37 \%$ \$40,001-\$80,000 & $40 \%$ & $37 \%$ & $34 \%$ & $41 \%$ \\
\hline Health characteristics & Overall & BC & $\mathbf{A B}$ & SK & ON \\
\hline \begin{tabular}{|l|} 
Cancer journey status: On \\
active surveillance or watchful \\
waiting, recently finished \\
treatment not started followup \\
visits, followup after \\
treatment, getting treatment for \\
recurrent cancer, finished \\
treatment for recurrent cancer \\
$(<3$ months $)$, receiving \\
treatment for metastatic \\
disease)
\end{tabular} & $\begin{array}{l}\text { Mode: } 63 \% \text { followup after } \\
\text { treatment }\end{array}$ & $64 \%$ & $56 \%$ & $61 \%$ & $67 \%$ \\
\hline $\begin{array}{l}\text { Overall health (very good/ } \\
\text { good, poor/very poor) }\end{array}$ & Mode: 94\% very good/good & $93 \%$ & $93 \%$ & $95 \%$ & $95 \%$ \\
\hline
\end{tabular}

AB: Alberta; BC: British Columbia; SK: Saskatchewan; ON: Ontario. 
Table 3. Usage and preferences for internet and paper sources

Q2. How easy or difficult was it for you (or other people helping you) to get information from each of the following sources below? ${ }^{1}$

\begin{tabular}{|l|c|c|c|}
\hline Source & $\begin{array}{c}\text { "Very easy" or } \\
\text { "Easy" }\end{array}$ & $\begin{array}{c}\text { "Difficult" or } \\
\text { "Very difficult" }\end{array}$ & $\begin{array}{l}\text { "Did NOT try to use this } \\
\text { source" or "Not applicable" }\end{array}$ \\
\hline $\begin{array}{l}\text { Internet (other than personal } \\
\text { email and online support groups) }\end{array}$ & $61 \%$ & $4 \%$ & $35 \%$ \\
\hline Books, brochures, or pamphlets & $75 \%$ & $6 \%$ & $19 \%$ \\
\hline
\end{tabular}

Q4. If you had easy access to each of the following sources, how much would you have wanted to get information about prostate cancer and/or treatments from each source? ${ }^{1}$

\begin{tabular}{|l|c|c|}
\hline Source & "Very much" or "Somewhat" & $\begin{array}{l}\text { "Would NOT want at all" or } \\
\text { "Not applicable” }\end{array}$ \\
\hline $\begin{array}{l}\text { Internet (other than personal } \\
\text { email and online support groups) }\end{array}$ & $68 \%$ & $32 \%$ \\
\hline Books, brochures, or pamphlets & $85 \%$ & $15 \%$ \\
\hline
\end{tabular}

${ }^{1}$ The question was followed with the instruction: Please check BEST response for EACH ROW. 


\begin{tabular}{|c|c|c|}
\hline Treatment & $\begin{array}{l}\text { Q9. Which of the following } \\
\text { treatments for prostate cancer } \\
\text { were you provided information } \\
\text { about? }^{1}\end{array}$ & $\begin{array}{l}\text { Q10. Which treatment(s) } \\
\text { have you received for } \\
\text { your prostate cancer? }^{1}\end{array}$ \\
\hline & "Yes" & "Yes" \\
\hline $\begin{array}{l}\square \\
\text { Surgery (prostatectomy-procedure where } \\
\text { they remove the prostate) }\end{array}$ & 1018 (75\%) & 549 (40\%) \\
\hline \begin{tabular}{|l|l}
$\square$ External beam radiation therapy \\
\end{tabular} & 881 (65\%) & $428(31 \%)$ \\
\hline$\square$ Seed implants (brachytherapy) & $772(57 \%)$ & $240(18 \%)$ \\
\hline $\begin{array}{l}\text { Hormone therapy or androgen-deprivation } \\
\text { therapy (ADT) (e.g., Lupron, Casodex, } \\
\text { Eligard) }\end{array}$ & $546(40 \%)$ & $343(25 \%)$ \\
\hline$\square$ Cryotherapy & $151(11 \%)$ & $12(1 \%)$ \\
\hline$\square$ Chemotherapy & $282(21 \%)$ & $27(2 \%)$ \\
\hline $\begin{array}{l}\square \\
\text { High-frequency ultrasound (HIFU) } \\
\text { therapy }\end{array}$ & $154(11 \%)$ & $19(1 \%)$ \\
\hline$\square$ Immune therapy & $13(1 \%)$ & $2(0 \%)$ \\
\hline $\begin{array}{l}\text { Active surveillance (no treatment received } \\
\text { unless the cancer becomes active then try } \\
\text { to cure the disease) }\end{array}$ & 487 (36\%) & 210 (15\%) \\
\hline $\begin{array}{l}\begin{array}{l}\text { Watchful waiting (no treatment received } \\
\text { unless the cancer causes symptoms, then } \\
\text { only treat symptoms) }\end{array} \\
\end{array}$ & $432(32 \%)$ & 150 (11\%) \\
\hline $\begin{array}{l}\square \\
\text { Complementary and alternative therapy } \\
\text { (e.g., herbal treatment) }\end{array}$ & $69(5 \%)$ & $31(2 \%)$ \\
\hline$\square$ None of the above or I cannot remember & & \\
\hline
\end{tabular}

${ }^{1}$ The question was followed with the instruction: Pease check ALL that apply. 


\section{Table 5. Provincial comparisons}

\section{Top person-specific sources}

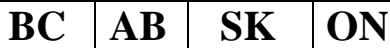

\section{Urologists}

[It was...] "Easy" or "very easy" to get information from this source

If I had easy access, I would "very much" or "somewhat" want information from this source

\begin{tabular}{|l|l|l|l|}
\hline $87 \%$ & $87 \%$ & $84 \%$ & $84 \%$ \\
\hline $96 \%$ & $97 \%$ & $96 \%$ & $97 \%$ \\
\hline
\end{tabular}

\section{General practitioner}

\begin{tabular}{|l|l|l|l|l|l|}
\hline [It was...] "Easy" or "very easy" to get information from this source & $75 \%$ & $75 \%$ & $75 \%$ & $63 \%$ \\
\hline
\end{tabular}

If I had easy access, I would "very much" or "somewhat" want information from this source

Other cancer patients

[It was...] "Easy" or "very easy" to get information from this source

If I had easy access, I would "very much" or "somewhat” want information from this source

Radiation oncologist

[It was...] "Easy" or "very easy" to get information from this source

If I had easy access, I would "very much" or "somewhat" want

information from this source

\begin{tabular}{|l|l|l|l|}
\hline $91 \%$ & $91 \%$ & $94 \%$ & $87 \%$ \\
\hline $48 \%$ & $42 \%$ & $53 \%$ & $42 \%$ \\
\hline $67 \%$ & $70 \%$ & $74 \%$ & $69 \%$ \\
\hline $56 \%$ & $45 \%$ & $54 \%$ & $58 \%$ \\
\hline $67 \%$ & $67 \%$ & $67 \%$ & $67 \%$ \\
\hline
\end{tabular}

Top barriers to obtaining information from...

\begin{tabular}{|l|l|l|l|l|l|}
\hline Your doctor or nurse - was "somewhat" or a "big” problem & $32 \%$ & $26 \%$ & $32 \%$ & $32 \%$ \\
\hline Not actually have enough time with doctor & $26 \%$ & $18 \%$ & $21 \%$ & $24 \%$ \\
\hline Worried about taking up a lot of doctor's time & \multicolumn{5}{|l|}{$\mid$\begin{tabular}{|l|l|}
\hline \\
\hline The internet - was “somewhat" or a "big" problem
\end{tabular}} \\
$\begin{array}{l}\text { Not knowing how to judge the quality of the information or what I } \\
\text { could trust }\end{array}$ & $59 \%$ & $61 \%$ & $65 \%$ & $67 \%$ \\
\hline Not knowing what information applied to my situation & $53 \%$ & $53 \%$ & $59 \%$ & $59 \%$ \\
\hline
\end{tabular}

Non-internet sources, such as books, pamphlets, etc — was "somewhat" or a "big" problem

Not knowing how to judge the quality of the information or what I could trust

Not knowing what information applied to my situation

\begin{tabular}{|l|l|l|l|}
$47 \%$ & $44 \%$ & $49 \%$ & $54 \%$ \\
\hline $46 \%$ & $45 \%$ & $57 \%$ & $52 \%$ \\
\hline
\end{tabular}

Top facilitators - would be "somewhat helpful" or "very helpful" to get the information you wanted

\begin{tabular}{l|l|l|l|l|l|}
\hline & Having someone to answer my questions in person & $90 \%$ & $87 \%$ & $94 \%$ & $91 \%$ \\
\hline $\begin{array}{l}\text { Having printed information provided to me (either in person or by } \\
\text { email) }\end{array}$ & $86 \%$ & $84 \%$ & $84 \%$ & $86 \%$ \\
\hline Information experience & $79 \%$ & $82 \%$ & $80 \%$ & $81 \%$ \\
\hline & I feel "well" or "very well" informed & $57 \%$ & $71 \%$, & $61 \%$ & $67 \%$ \\
\hline $\begin{array}{l}\text { Patients who underwent only surgery and received information about } \\
\text { external beam radiation therapy }\end{array}$
\end{tabular}

AB: Alberta; BC: British Columbia; SK: Saskatchewan; ON: Ontario. 